Article

\title{
Lipoprotein Lipase Inhibitor, Nordihydroguaiaretic Acid, Aggravates Metabolic Phenotypes and Alters HDL Particle Size in the Western Diet-Fed db/db Mice
}

\author{
Inhae Kang ${ }^{1}$, Miyoung Park ${ }^{2}$, Soo Jin Yang ${ }^{3(\mathbb{D})}$ and Myoungsook Lee ${ }^{2,4, * \mathbb{C}}$ \\ 1 Department of Food Science and Nutrition, Jeju National University, Jeju 63243, Korea; inhaek@jejunu.ac.kr \\ 2 Research Institute of Obesity Sciences, Sungshin Women's University, Seoul 01133, Korea; \\ mypinehill@naver.com \\ 3 Department of Food and Nutrition, Seoul Women's University, Seoul 01797, Korea; sjyang89@swu.ac.kr \\ 4 Department of Food and Nutrition, Sungshin Women's University, Seoul 01133, Korea \\ * Correspondence: mlee@sungshin.ac.kr; Tel.: +82-2-920-7211; Fax: +82-2-920-2078
}

Received: 24 May 2019; Accepted: 20 June 2019; Published: 22 June 2019

\begin{abstract}
Lipoprotein lipase (LPL) hydrolyzes triglycerides in lipoprotein to supply fatty acids, and its deficiency leads to hypertriglyceridemia, thereby inducing metabolic syndrome (MetSyn). Nordihydroguaiaretic acid (NDGA) has been recently reported to inhibit LPL secretion by endoplasmic reticulum (ER)-Golgi redistribution. However, the role of NDGA on dyslipidemia and MetSyn remains unclear. To address this question, leptin receptor knock out $(\mathrm{KO})-\mathrm{db} / \mathrm{db}$ mice were randomly assigned to three different groups: A normal AIN76-A diet (CON), a Western diet (WD) and a Western diet with $0.1 \%$ NDGA and an LPL inhibitor, (WD+NDGA). All mice were fed for 12 weeks. The LPL inhibition by NDGA was confirmed by measuring the systemic LPL mass and adipose LPL gene expression. We investigated whether the LPL inhibition by NDGA alters the metabolic phenotypes. NDGA led to hyperglycemia, hypertriglyceridemia, and hypercholesterolemia. More strikingly, the supplementation of NDGA increased the percentage of high density lipoprotein (HDL) small

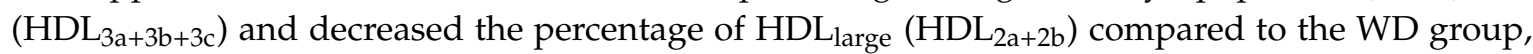
which indicates that LPL inhibition modulates HDL subclasses. was NDGA increased adipose inflammation but had no impact on hepatic stress signals. Taken together, these findings demonstrated that LPL inhibition by NDGA aggravates metabolic parameters and alters HDL particle size.
\end{abstract}

Keywords: lipoprotein lipase; nordihydroguaiaretic acid; dyslipidemia; HDL particle size

\section{Introduction}

Dyslipidemia is characterized by high levels of total cholesterol (TC), low-density lipoprotein (LDL) cholesterol, triglyceride (TG), and low levels of high density lipoprotein (HDL). It is considered a major risk factor for cardiovascular diseases (CVD) [1,2]. Among the components of dyslipidemia, a high level of LDL cholesterol (LDL-C) (>200mg/dl) is strongly associated with CVD events. However, atherosclerosis is common even in those with normal LDL levels $(90-130 \mathrm{mg} / \mathrm{dl})[3,4]$. A recent article also mentioned that LDL-C is not a good predictor of CVD with type 1 diabetes [5]. Furthermore, a systemic review of the effect of hypolipidemic agents on mortality showed that only $30 \%$ of atherosclerosis can be accounted for by LDL cholesterol, and that other factors, beyond the LDL cholesterol concentrations, are closely involved in the development of atherosclerosis $[5,6]$. This might indicate that LDL cholesterol may not discriminate between those who develop CVD and those who do not. HDL cholesterol has been considered a protective factor for lipid-related diseases due to its transport of excess cholesterol from peripheral tissues to the liver, as well as its inhibition of LDL cholesterol oxidation and inflammation [7]. Observations from epidemiological studies suggested 
that HDL cholesterol is negatively correlated with the risk of CVD [8], and this is generally accepted in clinical settings. However, recent clinical attempts to raise HDL cholesterol levels reported no or little correlation between HDL cholesterol and CVD $[9,10]$. A possible explanation for the neutral results is that there are various HDL phenotypes, depending on the specific settings (e.g., body fat content, body mass index, and types of stresses and diseases). HDL subclasses are divided by size and particle distribution; large HDL subclasses ( $\mathrm{HDL}_{2 \mathrm{a}}$ and $2 \mathrm{~b}$ ) are inversely related to metabolic

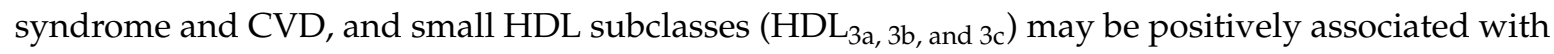
the diseases mentioned above [11,12]. HDL particles are continuously being remodeled by the reverse cholesterol transport (RCT) system. Plasma factors-'such as LPL, hepatic lipase, lecithin-cholesterol acyltransferase (LCAT), cholesteryl ester transfer protein (CETP), and phospholipid transfer proteins, or cell surface components like ATP-binding cassette (ABC), sub-family A, member 1 (ABCA1), ABC, sub-family G (WHITE), member 1 (ABCG1), and scavenger receptor class $B$, member 1 (SR-B1) - are involved in the alteration of the reverse cholesterol transport (RCT) system [7], which can modulate HDL metabolism. Thus far, limited evidence has been available regarding the interaction between the RCT system and HDL phenotypes. It has been reported that CETP increases small-size HDLs and small LDLs by interacting with LPL, increasing the risk of atherosclerosis [13]. In contrast, CETP inhibition resulted in increased HDL cholesterol, which suggests that CETP is a potential therapeutic target [14-17]. Similarly, the CETP inhibitor TA-8995 was also reported as causing a dose-dependent increase of HDL-C levels and Apo-A1 levels while reducing LDL-C levels and Apo-B levels [18], but several CETP inhibitors failed in clinical trials due to insufficient efficacy [19-21]. With regard to LPL, LPL-deficient human subjects had low levels of HDL cholesterol and hypertriglyceridemia, accompanied by increased levels of acylation-stimulating protein [22,23]. However, the effect of LPL on HDL subclasses has not yet been investigated.

Therefore, in this study, we investigated whether LPL inhibition affects dyslipidemia and HDL particle size distributions in Western diet (WD)-fed $\mathrm{db} / \mathrm{db}$ mice by analyzing the lipid profile, insulin resistance, and HDL subclasses of the mice.

\section{Results}

\subsection{LPL Inhibition by NDGA}

We first investigated whether nordihydroguaiaretic acid (NDGA) supplementation inhibits LPL levels. $\mathrm{Db} / \mathrm{db}$ mice were reported to have a lowered LPL mass and LPL gene expression, compared to C57BL/6 mice [24]. In this study, LPL mass and LPL gene expression in adipose tissue were significantly decreased in the WD+NDGA supplemented group compared to the WD group (Figure 1). 


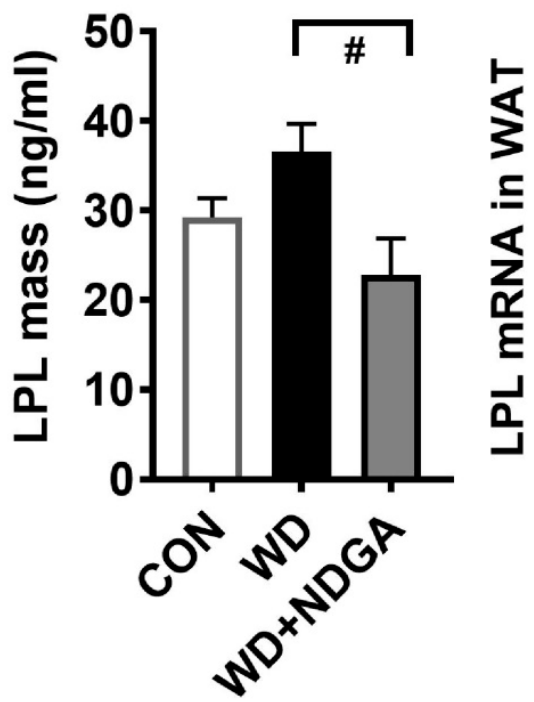

(a)

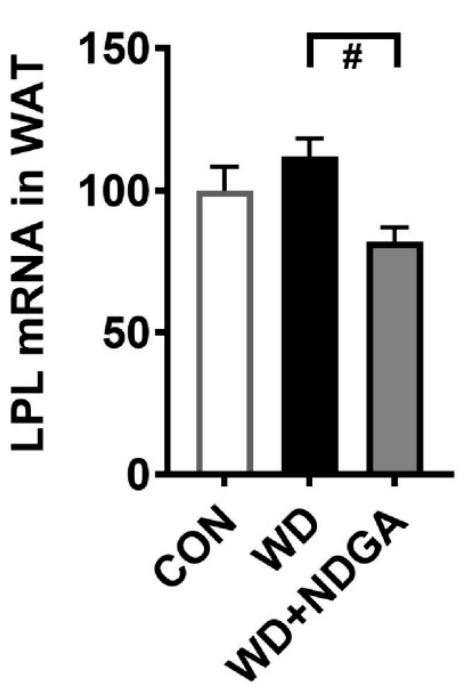

(b)

Figure 1. Effects of nordihydroguaiaretic acid (NDGA) on low-density lipoprotein (LPL) mass and LPL gene expression in $\mathrm{db} / \mathrm{db}$ mice: (a) LPL mass by ELISA; (b) LPL gene expression by qPCR in adipose tissue. Data are represented as the mean \pm SEM of three independent experiments. ${ }^{\#} p<0.05$, compared with the Western diet (WD) by one-way ANOVA, with Tukey's comparison test. WAT: White adipose tissue.

\subsection{Changes of Metabolic Parameters, Glucose and Insulin Levels by LPL Inhibitor, NDGA in db/db Mice}

Next, we investigated whether NDGA supplementation alters metabolic parameters. Mice fed with a WD which mimics human type-2 diabetes [25] significantly promoted body weight (BW) gain, compared to mice fed with a normal AIN76-A (CON) diet after 12 weeks of the diet (Figure 2A-C). NDGA supplementation was partially exacerbated BW and BW gain compared to the WD, without altering the food intake (Figure 2A-D). A similar trend was found in liver and visceral fat (epididymal) mass (Figure 2E,F).

We then asked whether NDGA aggravates type-2 diabetes-mediated abnormal glucose metabolism. The inclusion of NDGA led to an abnormal increase of blood glucose concentration, compared to the levels for the WD group (Figure 2G). While insulin levels had no difference in the NDGA group, compared to the WD group, the homeostasis model assessment of insulin resistance (HOMA-IR) index, an indicator of insulin resistance, was significantly increased by NDGA, compared to the WD group (Figure 2H,I). These data indicated that NDGA exacerbated the type-2 diabetes-induced glucose and insulin intolerance in $\mathrm{db} / \mathrm{db}$ mice. 


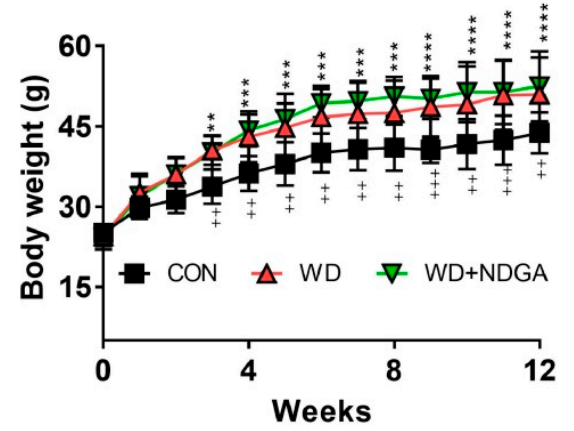

(a)

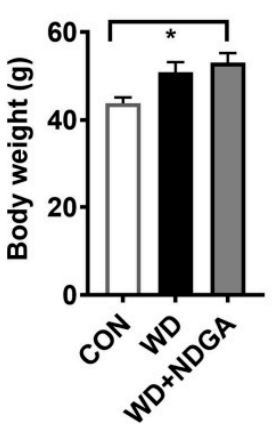

(b)

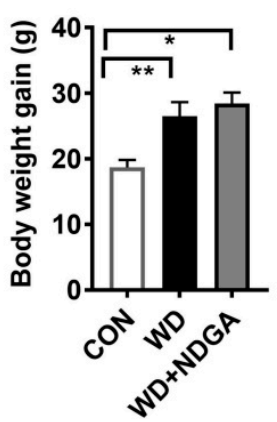

(c)

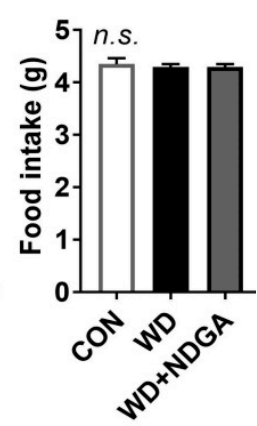

(d)

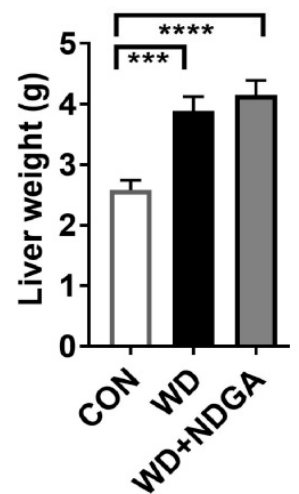

(e)

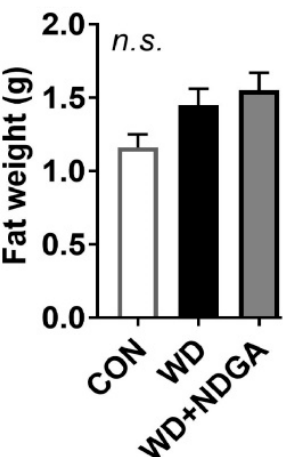

(f)

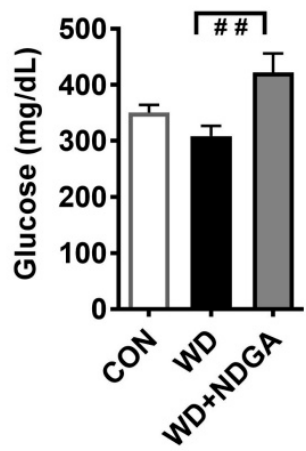

(g)

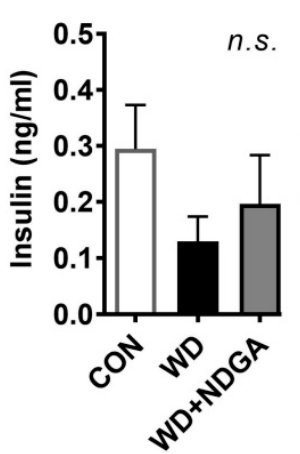

(h)

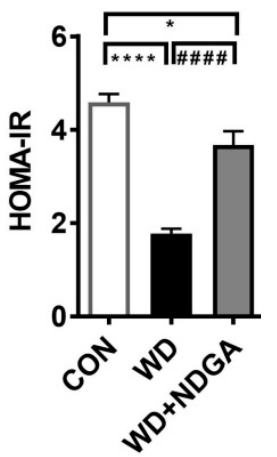

(i)

Figure 2. NDGA supplementation altered metabolic parameters, without altering the food intake. Six-week-old male db/db mice were fed with a control (normal AIN76-A (CON), black square, white bar), WD (red triangle, black bar), or WD+NDGA (green triangle, grey bar) diet for 12 weeks ( $n=10$ per group): (a) BW, g; (b) BW, g; (c) BW gain, g; (d) food intake, g/day; (e) liver weight, g; (f) fat weight, g; (g) glucose, mg/dl; (h) insulin, ng/mL; and (i) HOMA-IR. Data are expressed as mean \pm SEM $(n=10)$. (a) ${ }^{* *} p<0.01 ;{ }^{* * *} p<0.001 ;{ }^{* * * *} p<0.0001 \mathrm{CON}$ vs WD+NDGA; ${ }^{++} p<0.01$; $^{+++} p<0.001 ;^{++++} p<$ 0.0001 CON vs WD by two-way ANOVA, with Bonferroni's multiple comparisons test; $(\mathbf{b}-\mathbf{i}) * p<0.05$; ** $p<0.01$; ${ }^{* * *} p<0.001 ;{ }^{* * * *} p<0.0001$, compared with CON; ${ }^{\# \#} p<0.01$; ${ }^{\# \# \#} p<0.0001$, compared with WD by one-way ANOVA, with Tukey's comparison test.

\subsection{Changes of Lipid Profiles and HDL Particle Size by the LPL Inhibitor, NDGA, in db/db Mice}

We postulated that the inclusion of NDGA in the WD diet affects the plasma lipid profile. To address this hypothesis, the levels of the TG and total cholesterol were measured in plasma. TG and total cholesterol were even more up-regulated by NDGA compared to the WD control (Figure 3A,B).

Recently, MetSyn and ischemic stroke were reported to link small HDL3 and reduce large HDL2 levels [26,27]. We next were wondering whether NDGA affects HDL particle size in WD-fed db/db mice. The HDL peak size was decreased in both the WD and WD+NDGA groups compared to the WD group (Figure 3C). Furthermore, NDGA exerted profound effects on HDL particle size by damping the portions of $\mathrm{HDL}_{\text {large }}\left(\mathrm{HDL}_{2 \mathrm{a}+2 \mathrm{~b}}\right)$ and increasing the portions of $\mathrm{HDL}_{\text {small }}\left(\mathrm{HDL}_{3 \mathrm{a}+3 \mathrm{~b}+3 \mathrm{c}}\right)$, compared to the WD group (Figure 3D). These data demonstrated that supplementation with the LPL inhibitor, NDGA, leads to dyslipidemia and alters HDL subpopulations which are associated with MetSyn and CVD risk. 


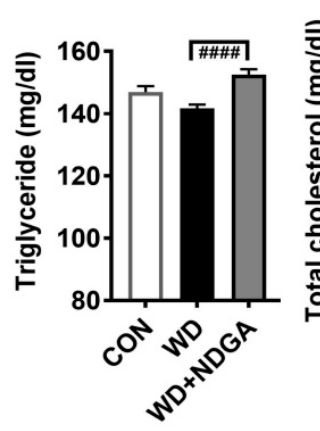

(a)

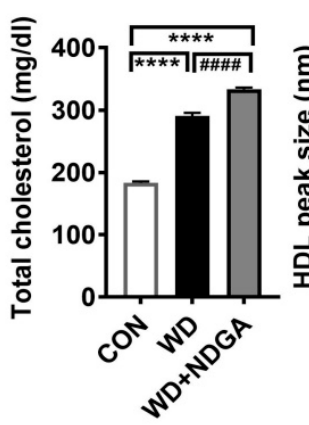

(b)

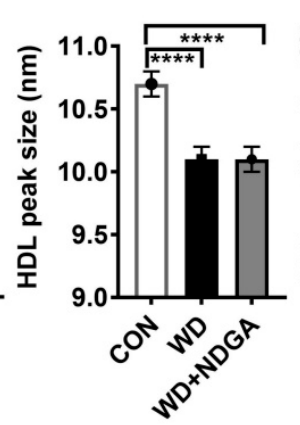

(c)

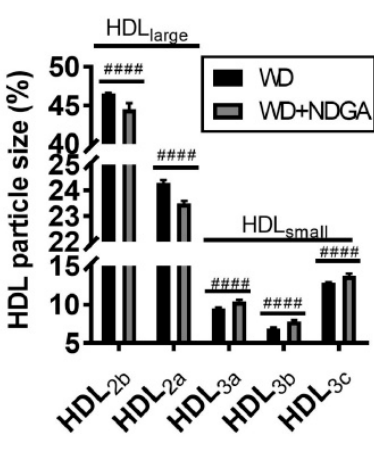

(d)

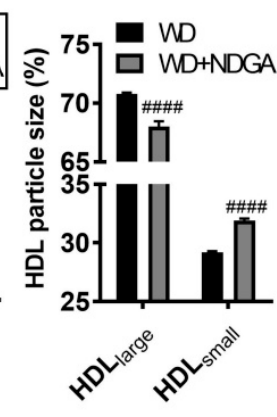

(e)

Figure 3. NDGA supplementation altered lipid profiles and high-density lipoprotein (HDL) subclasses. Six-week-old male $\mathrm{db} / \mathrm{db}$ mice were fed with the control (CON, white bar), WD (black bar), or WD+NDGA (grey bar) diet for 12 weeks ( $n=10$ per group): (a) Triglyceride, mg/dl; (b) total cholesterol, $\mathrm{mg} / \mathrm{dl}$; (c) HDL peak size, nm; (d) HDL particle size distribution, \%; (e) HDL particle size distribution,

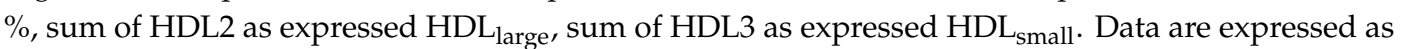
mean $\pm \operatorname{SEM}(n=10)$. ${ }^{* * *} p<0.0001$, compared with the CON ${ }^{\# \# \#} p<0.0001$, compared with the WD by one-way ANOVA, with Tukey's comparison test.

\subsection{Hepatic Stress Levels by the LPL Inhibitor, NDGA, in db/db Mice}

Given the significant alteration of plasma lipid and glucose profile by NDGA (Figures 2 and 3), we hypothesized that NDGA supplementation causes hepatic steatosis and endoplasmic reticulum (ER) stress. There was no difference in the aspartate aminotransferase (AST) and alanine aminotransferase (ALT) levels, which are known as systemic indicators of liver damage, between the WD and WD+NDGA groups (Figure 4A,B). Next, we investigated whether NDGA leads to a fatty liver by measuring the TG and cholesterol content in hepatic tissue. No differences were found in lipid contents between the NDGA-fed group and WD-fed group (Figure 4C,D). It is well known that hepatic ER stress is associated with hepatic steatosis [28], so we investigated whether NDGA altered hepatic stress signals. The WD diet-fed mice showed a marginal, not significant increase in c-Jun N-terminal kinases (JNK) activation by the induction of the phosphorylation of the JNK (pJNK) expression, compared with the CON group. However, there were no differences between NDGA and the WD (Figure 4E,F). Furthermore, pro-inflammatory markers, such as the phosphorylation-inhibitor kappa $\mathrm{B}(\mathrm{p}-\mathrm{ikB}) / \mathrm{ikB}$ ratio and tumor necrosis factor alpha (TNF $\alpha$ ) expression were not significantly different between NDGA and the WD (Figure $4 \mathrm{E}, \mathrm{G}, \mathrm{H}$ ). These data indicated that hepatic lipid accumulation and oxidative stress signals were not affected by the LPL inhibitor, NDGA. 


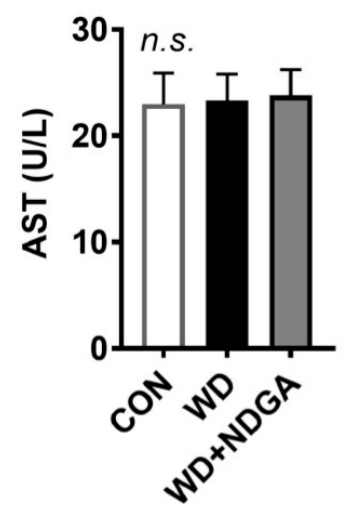

(a)

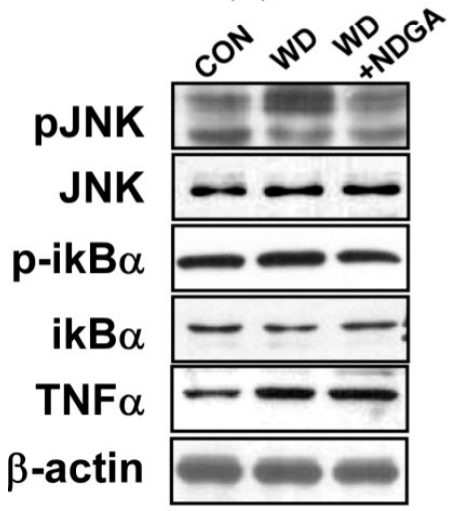

(e)

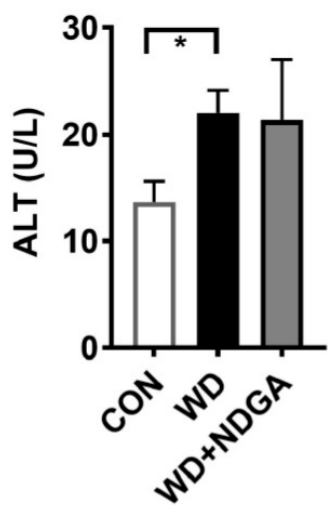

(b)

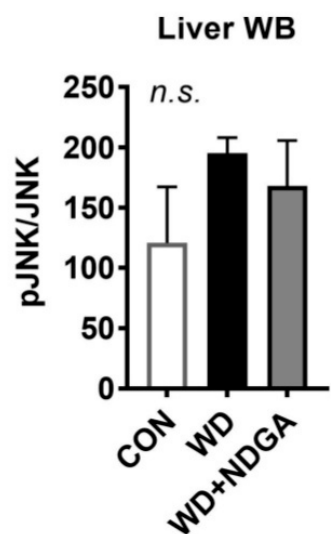

(f)

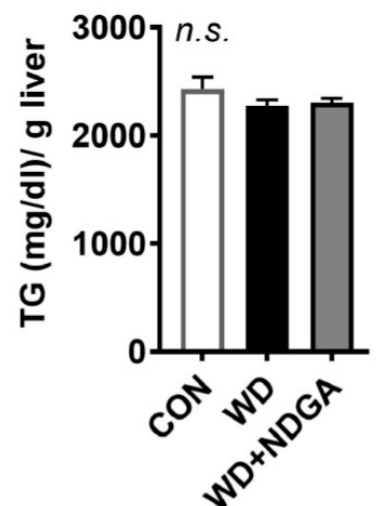

(c)

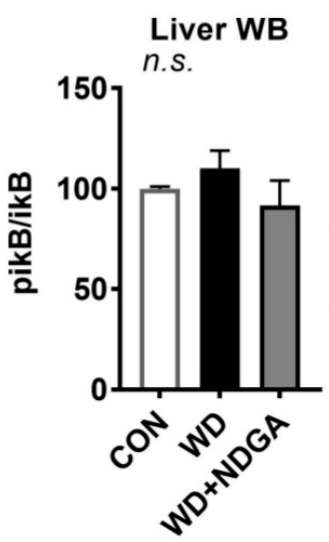

(g)

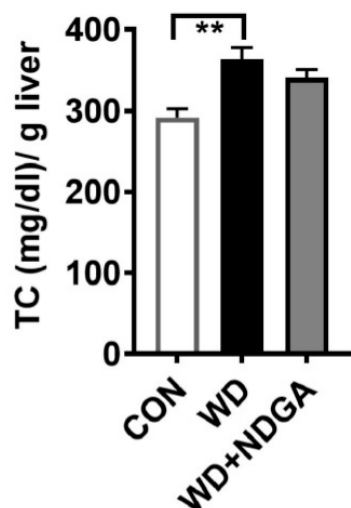

(d)

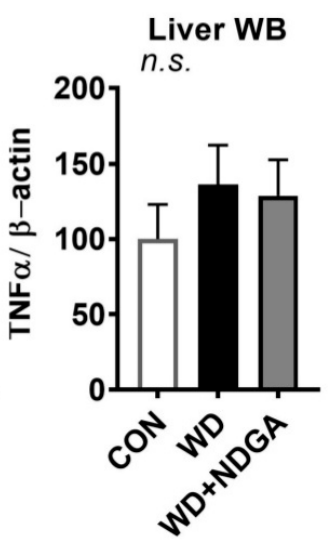

(h)

Figure 4. NDGA supplementation did not alter hepatic stress signaling. Six-week-old male db/db mice were fed with a control (CON, white bar), WD (black bar), or WD+NDGA (grey bar) diet for 12 weeks ( $n=10$ per group): (a) aspartate aminotransferase (AST) U/L; (b) alanine aminotransferase (ALT), U/L; (c) triglyceride (TG) contents in liver, $\mathrm{mg} / \mathrm{dl} / \mathrm{g}$ liver; (d) total cholesterol (TC) contents in the liver, $\mathrm{mg} / \mathrm{dl} / \mathrm{g}$; (e) hepatic western blot analysis of phosphorylation of c-Jun $\mathrm{N}$-terminal kinases (JNK), phosphorylation-inhibitor kappa B (p-ikB), and tumor necrosis factor alpha (TNF $\alpha$ ) in CON-, WD-, or WD+NDGA-fed db/db mice; (f) triplicate of western blot analysis of $\mathrm{pJNK} / \mathrm{JNK}$; (g) triplicate of western blot analysis of $\mathrm{p}-\mathrm{iKB} / \mathrm{iKB}$; and $(\mathbf{h})$ triplicate of western blot analysis of $\mathrm{TNF} \alpha / \beta$-actin. Data are expressed as the mean $\pm \operatorname{SEM}(n=10)$. ${ }^{*} p<0.05 ;{ }^{* *} p<0.01$, compared with the CON, by one-way ANOVA, with Tukey's comparison test.

\subsection{LPL Inhibition Alters Inflammation-Relation Makers in Epididymal Fat}

To determine whether the inclusion of NDGA alters adipose tissue metabolism and adipose inflammation, serum adiponectin levels and several inflammatory gene expressions were measured in epididymal fat. A marginal increase of fat mass (Figure 2) was associated with lowered plasma levels of adiponectin levels in the WD+NDGA group, compared to the WD group (Figure 5A). Consistently, the adipocyte-transcription factor, peroxisome proliferator-activated receptor gamma (PPAR $\gamma$ ), was also down-regulated by NDGA, compared to the WD group (Figure 5B). Despite there being no differences in monocyte chemoattractant protein-1 (MCP-1/CCL2) expression (Figure 5C)-which is one of the key chemokines that regulate the migration and infiltration of monocytes/macrophages, in the NDGA group-pro-inflammatory gene expressions, such as $\mathrm{TNF} \alpha$, were increased by NDGA in epididymal adipose tissue (Figure 5D). This suggests that LPL inhibition increased inflammation in adipose tissue. 


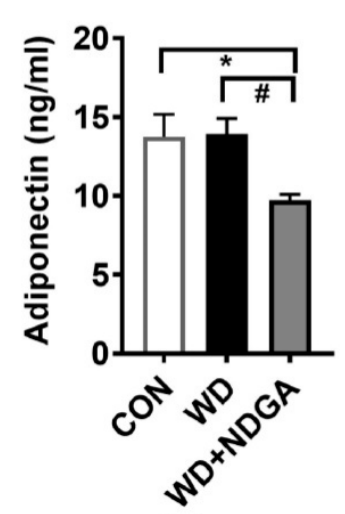

(a)

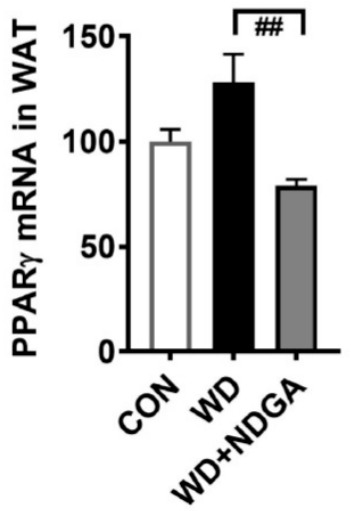

(b)

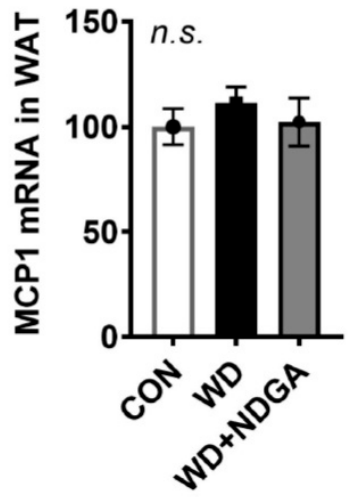

(c)

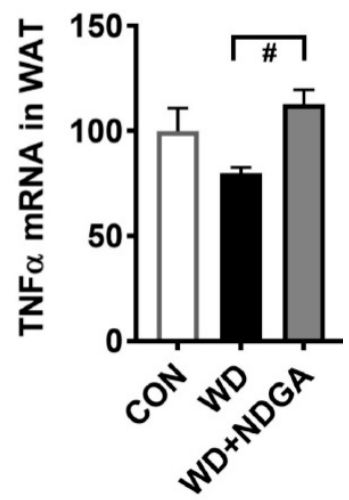

(d)

Figure 5. NDGA supplementation increased adipose inflammatory expression. Six-week-old male $\mathrm{db} / \mathrm{db}$ mice were fed with a control (CON, white bar), WD (black bar), or WD+NDGA (grey bar) diet for 12 weeks ( $n=8-12$ per group): (a) Serum adiponectin $(\mathrm{ng} / \mathrm{mL})$; (b) mRNA expression levels of proliferator-activated receptor gamma (PPAR $\gamma$ ); (c) MCP1; and (d) TNF $\alpha$ in epididymal adipose tissue, quantified by qPCR. Data are expressed as mean \pm SEM $(n=8-12) .{ }^{*} p<0.05$, compared with the CON; ${ }^{\#} p<0.05,{ }^{\# \#} p<0.01$ by one-way ANOVA, with Tukey's comparison test.

\section{Discussion}

LPL is a multifunctional enzyme produced by several tissues, such as adipose tissue, cardiac and skeletal muscle, and pancreatic tissue. LPL hydrolyzes the TG core of TG-rich lipoproteins, including chylomicrons, and very low-density lipoproteins (VLDL) as a rate-limiting enzyme [29]. Human subjects with LPL deficiency showed low HDL cholesterol and hypertriglyceridemia [22,23]. LPL deficiency had consistent phenotypes in not only in a human but also in rodent models. However, the effect of LPL inhibition on insulin resistance (IR) and lipid metabolism remains ambiguous. This study was specifically designed to test the hypothesis that the inclusion of NDGA, the functional role of which is to be an LPL inhibitor, exacerbates metabolic complications and alters HDL subclasses in the type-2 diabetes mice model, $\mathrm{db} / \mathrm{db}$ mice. Here, we demonstrated that the addition of NDGA in a WD marginally impedes metabolic parameters (Figure 2), alters lipid profiles (including HDL particle size (Figure 3) and systemic glucose levels (Figure 2)), and up-regulates adipose inflammation (Figure 5), all without changing hepatic stress signals (Figure 4) in $\mathrm{db} / \mathrm{db}$ mice. To our knowledge, this is the first study to report the previously unrecognized function of NDGA as an LPL inhibitor in the augmentation of metabolic dysfunction in $\mathrm{db} / \mathrm{db}$ mice and its possible association with the alteration of HDL subclass distribution.

The major distinctive metabolic consequence that we first noticed was that NDGA differentially impacted metabolic parameters in $\mathrm{db} / \mathrm{db}$ mice. $\mathrm{Db} / \mathrm{db}$ mice are well known type-2 diabetes-animal models and showed a significant increase in BW after four weeks of being fed a standard diet [30]. Consistently, our data also showed that $\mathrm{db} / \mathrm{db}$ mice had a continuous increase of BW. A WD did stimulate BW up-regulation compared to CON. However, the additional supplementation of NDGA did not impede metabolic parameters such as BW or organ weight compared to a WD (Figure $2 \mathrm{~A}, \mathrm{~B}$ ), which may be due to its plateau of $\mathrm{db} / \mathrm{db}$ mice. Interestingly, NDGA caused hyperglycemia and the induction of HOMA-IR levels (Figure 2G-I). In agreement with this notion, Laperrousaz et al. recently reported that neuronal LPL deficiency causes body weight gain and induces the early dysfunction of glucose homeostasis [31]. However, the phenotypes of LPL deficiency may vary, depending on the tissue. The adipose tissue-specific LPL deficiency model, unlike the neuronal LPL deficiency model, showed no difference in body weight but did show hypertriglyceridemia [32]. Strikingly, on the other hand, mice with an over-expression of adipose tissue-specific LPL and fed with high-fat diet had improved glucose intolerance but no difference in body weight [33]. This might indicate the pivotal role of LPL on glucose and lipid metabolism. NDGA has been reported to inhibit LPL secretion by 
ER-Golgi redistribution [34], but it is still unclear how much and what types of tissue are affected by NDGA. Though we measured LPL mass and LPL gene expression in adipose tissue (Figure 1), further study is necessary to determine the dose-duration LPL activity caused by NDGA in different tissues. Moreover, we have used $\mathrm{db} / \mathrm{db}$ mice fed with a WD as our animal model, but we did not check the impact of NDGA on control mice strains such as C57BL/6J. Future investigations are required to test this hypothesis.

NDGA supplementation leads to dyslipidemia, which is evidenced by an increase in plasma TG and TC and a decrease in the HDL peak size, as well as HDL subclass distributions (Figure 3). In agreement with this notion, Murase et al. reported that the inhibition of LPL caused hypertriglyceridemia in humans [35], and Berbee et al. reported that human APOC1 transgenic mice, who had a down-regulated LPL, showed hypertriglyceridemia and hypercholesterolemia [36]. A reduced HDL2, which is large $\mathrm{HDL}$, is associated with angiographically-defined arteriosclerosis [37,38]. In our study, NDGA supplementation in a WD caused a significant reduction of HDL2 and the induction of HDL3 (Figure 3). This indicated that the modulation of the RCT enzyme is able to regulate HDL particle size. We expected that the complexities of HDL metabolism might be explained by the relation between the RCT system and HDL particle size distribution. The LPL inhibition increased the proportion of

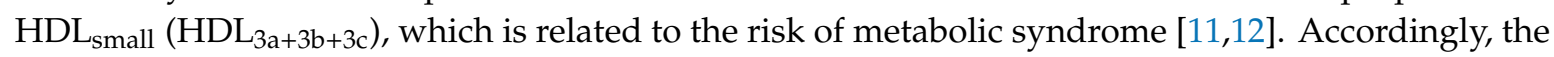
protective effect of $\mathrm{HDL}_{\text {large }}\left(\mathrm{HDL}_{2 \mathrm{a}+2 \mathrm{~b}}\right)$ against metabolic syndrome was attenuated by LPL inhibition, strengthening the effect of $\mathrm{HDL}_{\mathrm{small}}\left(\mathrm{HDL}_{3 \mathrm{a}+3 \mathrm{~b}+3 \mathrm{c}}\right)$ on metabolic complications. Furthermore, an increased plasma TC caused by LPL inhibition may be due to increased levels of circulated LDL and/or an altered exchange of cholesterol ester-rich HDL. VLDL-TG may be exchanged to HDL, resulting in decreased levels of VLDL-TG due to LPL inhibition. While we cannot rule out the significant effects of other regulating factors of the RCT system, it is clear that, in the setting of obesity and hyperlipidemia, LPL inhibition-mediated alterations are associated with an increased risk of metabolic complications. Moreover, the findings in this study suggest that LPL is highly associated with HDL subclasses. Different HDL properties have been reported to associate with several diseases such as ischemic stroke [27], CVD [12], and hyperglycemia [39]. Our previous study also revealed that a high level of HDL3 is associated with large waist circumference and MetSyn [40]. In agreement of this notion, a recent paper reported the association between Metsyn and HDL particle size [26,41]. Several studies have shown that HDL3 exerts a more powerful protective action against LDL oxidation than HDL2 [42,43]. However, the effect of the individual HDL subfraction on the risk of diseases is still ambiguous. We did not check detailed lipoprotein profiles (such as VLDL, LDL, and HDL levels), the clearance of TG, and lipoprotein receptor expressions in the liver or skeletal muscle, which may affect TG metabolisms caused by NDGA, so that aspect needs to be investigated. Moreover, future studies using an LPL agonist alone or in combination with a CETP inhibitor need to be conducted in order to investigate the possibility of LPL as a therapeutic target of dyslipidemia and CVD.

Targeting both liver and adipose tissue on the modulation of lipid accumulation would be the goal for intervention strategies to control MetSyn and obesity-related metabolic complications. The present study was designed to determine the diminished lipid metabolism of NDGA supplementation in adipose and the liver and to identify the metabolic alterations caused by NDGA in both tissues. We expected to find a higher ER stress and hepatic inflammation status due to NDGA, which is evidenced by the increased plasma TG and TC level, as well as HDL large. Unexpectedly, hepatic lipid accumulation and hepatic stress signals were not altered by the LPL inhibitor, NDGA (Figure 4). Since many reports demonstrated that hepatic LPL levels are relatively low compared with other tissues [44], little attention has been paid to hepatic lipid metabolism. Recent evidence reported that hepatic TG, cholesterol contents, and/or glucose homeostasis did not change due to hepatic LPL deficiency [45]. Thus, we assumed that NDGA, LPL inhibitor-mediated hypertriglyceridemia, hypercholesterolemia, hypoadiponetimia, and hyperglycemia are compensated due to the action of hepatic lipid homeostasis caused by LPL. However, further study is needed to confirm the hepatic lipid homeostasis action of NDGA in vitro or the control strain of mice. 
Lastly, we assessed the impact of NDGA on adiposity as well as adipose tissue inflammation. The fat weight did not reach statistical significance among the groups despite the trend of a stepwise incline in mice fed with $\mathrm{WD}+\mathrm{NDGA}>\mathrm{WD}>\mathrm{CON}$ diets (Figure 2). The adiponectin levels were decreased due to LPL inhibition (Figure 5), which may be due to decreased insulin sensitivity. TNF $\alpha$ mediates both apoptosis and inflammation, stimulating an inflammatory cascade through the non-canonical pathway of NF-kappaB activation, leading to an increased nuclear RelB and p52 [46]. TNF $\alpha$ was increased in NDGA-treated mice (Figure 5), suggesting that TNF $\alpha$-related mechanisms in fat cells, such as the secretion of adipokines (e.g., adiponectin), ER stress, and the disturbance of insulin-signaling pathways were changed by LPL inhibition through NDGA. All of these alterations imply the insulin resistance was aggravated by LPL inhibition. However, we still did not measure the systemic inflammatory cytokines or non-canonical pathway of NF- $\mathrm{kB}$ activation in adipose tissue. Further studies should be conducted to validate these hypotheses.

In summary, we tested the innovative idea that the inclusion of NDGA in a WD diet could exacerbate the leptin receptor knock out $(\mathrm{KO})$ mice-mediated metabolic dysfunction. We identified that NDGA, as an LPL inhibitor, effectively worsened obesity and metabolic complications including dyslipidemia, HDL particle size alteration, and adipose inflammation. These initial findings in rodents must be confirmed by dose and duration experiments in rodents and humans in future studies. A major limitation of our study is that it is still hard to identify the HDL phenotype by NDGA, an LPL inhibitor. HDL is a highly heterogeneous lipoprotein class, so further study is required by measure HDL concentration, size, density, shape, apolipoprotein compositions, and complete lipoprotein distribution. We are currently investigating a rodent study by using apolipoprotein E-knockout (apoE KO) mice as our mice model to induce atherosclerosis and identify the role of the LPL inhibitor NDGA on CVD risk and HDL subpopulations. Nevertheless, we believe that our study sheds new insight into how NDGA alters metabolic phenotypes and HDL particle size.

\section{Materials and Methods}

\subsection{Care of Animals and Experimental Groups}

Male wild-type and db/db mice were provided by Japan SLC Inc. (Tokyo, Japan). Thirty $\mathrm{db} / \mathrm{db}$ mice were maintained in a temperature- and humidity-controlled room on a $12 \mathrm{~h}$ light/dark cycle and fed the irradiated standard, American Institute of Nutrition (AIN)-76A. After one week of the acclimation period, $30 \mathrm{db} / \mathrm{db}$ mice, at approximately 6 weeks of age, were divided into three experimental groups: 1) $\mathrm{db} / \mathrm{db}$ mice with a standard diet (AIN-76A diet; CON), 2$) \mathrm{db} / \mathrm{db}$ mice with a WD (21\% milk fat, DYET \#102068, Dyets Inc., Bethelehem, PA, USA: WD), and 3) db/db mice with a Western diet and $0.1 \%$ NDGA as an LPL inhibitor (WD+NDGA), with unlimited access to food and water (Table 1). NDGA was purchased from Dyets Inc. and delivered as a pre-mixed powder diet. The study protocol conformed to the specifications outlined in the National Institutes of Health's Guiding Principles for the Care and Use of Laboratory Animals and was approved by the Institutional Animal Care and Use Committee of Sungshin Women's University (01.05.2008, \# SSWU AEC 2008-001).

Table 1. Diet composition.

\begin{tabular}{cccc}
\hline & $\begin{array}{c}\text { AIN76-A Diet } \\
\text { (CON) }\end{array}$ & $\begin{array}{c}\text { Western Diet } \\
\text { (WD) }\end{array}$ & $\begin{array}{c}\mathbf{0 . 1 \%} \text { NDGA Mixed Western Diet } \\
\text { (WD + NDGA) }\end{array}$ \\
\hline Ingredient & grams/ Kg & grams/ Kg & grams/ Kg \\
\hline Casein & 200 & 195 & 195 \\
DL-Methionine & 3 & 3 & 3 \\
Cornstarch & 150 & 150 & 150 \\
Sucrose & 499.99 & 341.46 & 340.46 \\
Cellulose & 50 & 50 & 50 \\
Milk Fat & $50($ corn-oil) & 210 & 210 \\
Cholesterol & & 1.5 & 1.5 \\
\hline
\end{tabular}


Table 1. Cont.

\begin{tabular}{cccc}
\hline & $\begin{array}{c}\text { AIN76-A Diet } \\
\text { (CON) }\end{array}$ & $\begin{array}{c}\text { Western Diet } \\
\text { (WD) }\end{array}$ & $\begin{array}{c}\mathbf{0 . 1 \%} \text { NDGA Mixed Western Diet } \\
\text { (WD + NDGA) }\end{array}$ \\
\hline Ingredient & grams/ Kg & grams/ Kg & grams/ Kg \\
\hline Vitamin Mix \#310035 & 12 & 10 & 10 \\
Mineral Mix \#200000 & 35 & 35 & 35 \\
Calcium Carbonate & & 4 & 4 \\
Ethoxyquin & 0.01 & 0.04 & 0.04 \\
NDGA & & & 1 \\
\hline
\end{tabular}

\subsection{Blood and Tissue Collection}

After 12 weeks of treatment, mice, fasted overnight, were anesthetized with diethyl ether (Duksan, Seoul, South Korea), and blood was collected from the carotid artery. After blood collection, the tissues were harvested, weighed, and stored at $-80^{\circ} \mathrm{C}$ until further analysis.

\subsection{Measurements of Biochemical Parameters}

Plasma glucose (QuantiChrom Glucose Assay Kit, Hayward, CA, USA), TG, TC (Boeringer mannheim, Germany), aspartate aminotransferase (AST), and the alanine aminotransferase (ALT) assay (IFCC, Human 12021, Wiesbaden, Germany) were measured by an absorbance reader (Multiskan spectrum, Thermo Scientific, Waltham, MA, USA). Commercially available ELISA kits were used for the measurement of plasma adiponectin (AdipoGen, Incheon, Korea) and serum insulin (Mercodia AB, Uppsala, Sweden).

\subsection{HDL Particle Size Phenotyping}

HDL particle size phenotypes were determined as previously described [40]. The HDL fraction was isolated by the new micro-ultracentrifugation at $1.063<\mathrm{d}<1.21 \mathrm{~g} / \mathrm{mL}$, with a high relative centrifugal field $(\mathrm{RCF})$ of $1,050,000 \times g$ for $140 \mathrm{~min}$ (Hitachi CS150GXL, S140AT fixed angle rotor, Tokyo, Japan). The final HDL preparations were dialyzed, and $10 \mu \mathrm{L}$ of HDL, was loaded onto $4-30 \%$ polyacrylamide non-denaturating gradient gels (LPE gels 4/30, CBS Scientific Company, Inc., Del Mar, CA, USA), which were run by a Pore Gradient Lipoprotein electrophoresis system (PGGE, CSI Scientific Electrophoresis LPE-4003; C.B.S. Scientific Inc., Solana Beach, CA, USA). They were pre-run at 80 Voltage for $20 \mathrm{~min}$ with a non-SDS buffer, and the voltage was applied in the following way: $100 \mathrm{~V}$ for $2 \mathrm{~h}, 130$ Voltage for $4 \mathrm{~h}, 150$ Voltage for $18 \mathrm{~h}$, and 120 Voltage for $2 \mathrm{~h}$. The Coomassie Blue G-250 stained gels were analyzed using the ImageMaster ID software 4.0 (Amersham Pharmacia Biotech, Buckinghamshire, UK). The diameter of the lipoprotein band was calibrated by computing a log-linear standard curve with high molecular weight calibration kit standards (thyroglobulin, $17 \mathrm{~nm}$; ferritin, $12.2 \mathrm{~nm}$; catalase, $10.4 \mathrm{~nm}$; LDH, $8.2 \mathrm{~nm}$; BSA, $7.1 \mathrm{~nm}$; Amersham Pharmacia Biotech) as the relative migration distances.

\subsection{Preheparin LPL Mass}

The preheparin LPL mass was measured using ELISA kits (LPL ELISA kit, Daiichi Pure Chemicals, Tokyo, Japan), according to the manufacturer's protocol.

\subsection{Gene Expression Analysis (Quantitative PCR)}

The total RNA was isolated by a Trizol reagent (Invitrogen, Carlsbad, CA, USA). The RNA was subsequently reverse-transcribed to cDNA using the ThermoScript RT-PCR system (Invitrogen), following the manufacturer's instructions. The mRNA levels were measured by real-time PCR using a Mini Opiticon (Bio-Rad Laboratories, Hercules, CA, USA). PCR primers for the target genes were designed using an online version of the primer 3 software. Quantitative PCR data were evaluated 
using the comparative critical threshold $(\mathrm{Ct})$ method and normalized to the average of the endogenous control gene, $\beta$-actin (primer sequences are shown in Table 2). The relative gene expression was calculated by the delta $\mathrm{Ct}$ method.

Table 2. Primer sequences for qPCR.

\begin{tabular}{ccc}
\hline Gene & Forward/Reverse & Sequence $\left(\mathbf{5}^{\prime} \mathbf{- \mathbf { 3 } ^ { \prime }}\right)$ \\
\hline \multirow{2}{*}{ mPPAR $\gamma$} & Forward & aac tgc agg gtg aaa ctc tgg gag att ctc $\mathrm{c}$ \\
\cline { 2 - 3 } & Reverse & gga ttc agc aac cat tgg gtc agc tct \\
\hline \multirow{2}{*}{ mFAT/CD36 } & Forward & tac ctg gga gtt ggc gag \\
\cline { 2 - 3 } & Reverse & ttg cca cgt cat ctg ggt tt \\
\cline { 2 - 3 } mTNF $\alpha$ & Forward & ctg agg tca atc tgc cca agt ac \\
\cline { 2 - 3 } m $\beta$-actin & Reverse & ctt cac aga gca atg act cca aag \\
\cline { 2 - 3 } & Forward & cct cta tgc caa cac agt gc \\
\hline
\end{tabular}

\subsection{Western Blotting Analysis}

The liver was collected, and the protein was isolated with an ice-cold radioimmune precipitation assay (RIPA) buffer (Thermo Scientific) containing protease inhibitors (Sigma). Proteins were fractionated using $8 \%$ or 10\% SDS-PAGE, transferred to polyvinylidene difluoride (PVDF) membranes and incubated with the relevant antibodies. Chemiluminescence from the enhanced chemiluminescence (ECL) (Western Lightning) solution was detected with ChemiDoc (Bio-Rad). Polyclonal or monoclonal antibodies which target phosphor- c-Jun N-terminal kinases (JNK), JNK, phosphor- inhibitor kappa B (p-ikB), ikB, and $\beta$-actin were purchased from Cell Signaling Technology.

\subsection{Statistical Analysis}

All the data were expressed as the means and standard error (SE), and statistical calculations were performed using the t-test and ANOVA (one-way analysis of variance), with Tukey's and Bonferroni's multiple comparison tests. The results were considered significant if $p<0.05$ (GraphPad Prism Version 7.0, La Jolla, CA, USA).

Author Contributions: Conceptualization, M.L.; methodology, M.P.; investigation, I.K.; data curation, I.K.; writing—original draft preparation, I.K. and S.J.Y.; writing—review and editing, M.P., S.J.Y. and M.L.; visualization, I.K.; supervision, M.L.; project administration, M.L.; funding acquisition, M.L.

Funding: This research received no external funding.

Conflicts of Interest: The authors declare no conflict of interest.

\section{Abbreviations}

ABCA1 ATP-binding cassette (ABC), sub-family A, member 1

ABCG1 ABC, sub-family $G$, member 1

ALT Alanine aminotransferase

AST Aspartate aminotransferase

CETP Cholesteryl ester transfer protein

CON Control, AIN76-A diet

CVD Cardiovascular diseases

ER Endoplasmic reticulum

HDL High-density lipoprotein

IkB Inhibitor kappa B

JNK C-Jun N-terminal kinases

LDL Low-density lipoprotein 


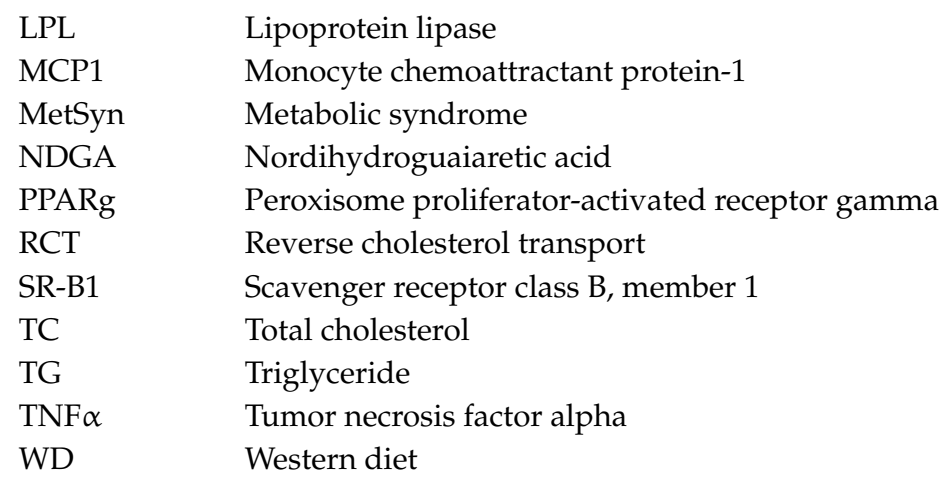

\section{References}

1. Yusuf, S.; Hawken, S.; Ounpuu, S.; Dans, T.; Avezum, A.; Lanas, F.; McQueen, M.; Budaj, A.; Pais, P.; Varigos, J.; et al. Effect of potentially modifiable risk factors associated with myocardial infarction in 52 countries (the INTERHEART study): Case-control study. Lancet 2004, 364, 937-952. [CrossRef]

2. Walldius, G.; Jungner, I.; Holme, I.; Aastveit, A.H.; Kolar, W.; Steiner, E. High apolipoprotein B, low apolipoprotein A-I, and improvement in the prediction of fatal myocardial infarction (AMORIS study): A prospective study. Lancet 2001, 358, 2026-2033. [CrossRef]

3. Law, M.R.; Wald, N.J. Risk factor thresholds: Their existence under scrutiny. BMJ 2002, 324, 1570-1576. [CrossRef] [PubMed]

4. Akosah, K.O.; Schaper, A.; Cogbill, C.; Schoenfeld, P. Preventing myocardial infarction in the young adult in the first place: How do the National Cholesterol Education Panel III guidelines perform? J. Am. Coll. Cardiol. 2003, 41, 1475-1479. [CrossRef]

5. Hero, C.; Svensson, A.M.; Gidlund, P.; Gudbjornsdottir, S.; Eliasson, B.; Eeg-Olofsson, K. LDL cholesterol is not a good marker of cardiovascular risk in Type 1 diabetes. Diabet. Med. 2016, 33, 316-323. [CrossRef] [PubMed]

6. Studer, M.; Briel, M.; Leimenstoll, B.; Glass, T.R.; Bucher, H.C. Effect of different antilipidemic agents and diets on mortality: A systematic review. Arch. Intern. Med. 2005, 165, 725-730. [CrossRef] [PubMed]

7. Lewis, G.F.; Rader, D.J. New insights into the regulation of HDL metabolism and reverse cholesterol transport. Circ. Res. 2005, 96, 1221-1232. [CrossRef]

8. Emerging Risk Factors, C.; Di Angelantonio, E.; Gao, P.; Pennells, L.; Kaptoge, S.; Caslake, M.; Thompson, A.; Butterworth, A.S.; Sarwar, N.; Wormser, D.; et al. Lipid-related markers and cardiovascular disease prediction. JAMA 2012, 307, 2499-2506. [CrossRef]

9. Group, A.S.; Ginsberg, H.N.; Elam, M.B.; Lovato, L.C.; Crouse, J.R., 3rd; Leiter, L.A.; Linz, P.; Friedewald, W.T.; Buse, J.B.; Gerstein, H.C.; et al. Effects of combination lipid therapy in type 2 diabetes mellitus. N. Engl. J. Med. 2010, 362, 1563-1574. [CrossRef]

10. Investigators, A.-H.; Boden, W.E.; Probstfield, J.L.; Anderson, T.; Chaitman, B.R.; Desvignes-Nickens, P.; Koprowicz, K.; McBride, R.; Teo, K.; Weintraub, W.; et al. Niacin in patients with low HDL cholesterol levels receiving intensive statin therapy. N. Engl. J. Med. 2011, 365, 2255-2267. [CrossRef]

11. Asztalos, B.F.; Tani, M.; Schaefer, E.J. Metabolic and functional relevance of HDL subspecies. Curr. Opin. Lipidol. 2011, 22, 176-185. [CrossRef] [PubMed]

12. Krauss, R.M. Lipoprotein subfractions and cardiovascular disease risk. Curr. Opin. Lipidol. 2010, $21,305-311$. [CrossRef] [PubMed]

13. Kastelein, J.J. Refocusing on use of cholesteryl ester transfer protein inhibitors. Am. J. Cardiol. 2007, 100, 47-52. [CrossRef] [PubMed]

14. Krishna, R.; Anderson, M.S.; Bergman, A.J.; Jin, B.; Fallon, M.; Cote, J.; Rosko, K.; Chavez-Eng, C.; Lutz, R.; Bloomfield, D.M.; et al. Effect of the cholesteryl ester transfer protein inhibitor, anacetrapib, on lipoproteins in patients with dyslipidaemia and on 24-h ambulatory blood pressure in healthy individuals: Two double-blind, randomised placebo-controlled phase I studies. Lancet 2007, 370, 1907-1914. [CrossRef] 
15. Bloomfield, D.; Carlson, G.L.; Sapre, A.; Tribble, D.; McKenney, J.M.; Littlejohn, T.W., 3rd; Sisk, C.M.; Mitchel, Y.; Pasternak, R.C. Efficacy and safety of the cholesteryl ester transfer protein inhibitor anacetrapib as monotherapy and coadministered with atorvastatin in dyslipidemic patients. Am. Heart J. 2009, 157, 352-360.e2. [CrossRef] [PubMed]

16. Nicholls, S.J.; Brewer, H.B.; Kastelein, J.J.; Krueger, K.A.; Wang, M.D.; Shao, M.; Hu, B.; McErlean, E.; Nissen, S.E. Effects of the CETP inhibitor evacetrapib administered as monotherapy or in combination with statins on HDL and LDL cholesterol: a randomized controlled trial. JAMA 2011, 306, 2099-2109. [CrossRef] [PubMed]

17. Ballantyne, C.M.; Miller, M.; Niesor, E.J.; Burgess, T.; Kallend, D.; Stein, E.A. Effect of dalcetrapib plus pravastatin on lipoprotein metabolism and high-density lipoprotein composition and function in dyslipidemic patients: Results of a phase IIb dose-ranging study. Am. Heart J. 2012, 163, 515-521.e3. [CrossRef]

18. Hovingh, G.K.; Kastelein, J.J.; van Deventer, S.J.; Round, P.; Ford, J.; Saleheen, D.; Rader, D.J.; Brewer, H.B.; Barter, P.J. Cholesterol ester transfer protein inhibition by TA-8995 in patients with mild dyslipidaemia (TULIP): A randomised, double-blind, placebo-controlled phase 2 trial. Lancet 2015, 386, 452-460. [CrossRef]

19. Sheridan, C. CETP inhibitors boost 'good' cholesterol to no avail. Nat. Biotechnol. 2016, 34, 5-6. [CrossRef]

20. Group, H.T.R.C.; Bowman, L.; Hopewell, J.C.; Chen, F.; Wallendszus, K.; Stevens, W.; Collins, R.; Wiviott, S.D.; Cannon, C.P.; Braunwald, E.; et al. Effects of Anacetrapib in Patients with Atherosclerotic Vascular Disease. N. Engl. J. Med. 2017, 377, 1217-1227. [CrossRef]

21. Schwartz, G.G.; Olsson, A.G.; Abt, M.; Ballantyne, C.M.; Barter, P.J.; Brumm, J.; Chaitman, B.R.; Holme, I.M.; Kallend, D.; Leiter, L.A.; et al. Effects of dalcetrapib in patients with a recent acute coronary syndrome. $N$. Engl. J. Med. 2012, 367, 2089-2099. [CrossRef] [PubMed]

22. Sprecher, D.L.; Harris, B.V.; Stein, E.A.; Bellet, P.S.; Keilson, L.M.; Simbartl, L.A. Higher triglycerides, lower high-density lipoprotein cholesterol, and higher systolic blood pressure in lipoprotein lipase-deficient heterozygotes. A preliminary report. Circulation. 1996, 94, 3239-3245. [CrossRef] [PubMed]

23. Paglialunga, S.; Julien, P.; Tahiri, Y.; Cadelis, F.; Bergeron, J.; Gaudet, D.; Cianflone, K. Lipoprotein lipase deficiency is associated with elevated acylation stimulating protein plasma levels. J. Lipid Res. 2009, 50, 1109-1119. [CrossRef] [PubMed]

24. Davis, R.C.; Castellani, L.W.; Hosseini, M.; Ben-Zeev, O.; Mao, H.Z.; Weinstein, M.M.; Jung, D.Y.; Jun, J.Y.; Kim, J.K.; Lusis, A.J.; et al. Early hepatic insulin resistance precedes the onset of diabetes in obese C57BLKS-db/db mice. Diabetes 2010, 59, 1616-1625. [CrossRef] [PubMed]

25. Burke, S.J.; Batdorf, H.M.; Burk, D.H.; Noland, R.C.; Eder, A.E.; Boulos, M.S.; Karlstad, M.D.; Collier, J.J. $\mathrm{db} / \mathrm{db}$ Mice Exhibit Features of Human Type 2 Diabetes That Are Not Present in Weight-Matched C57BL/6J Mice Fed a Western Diet. J. Diabetes Res. 2017, 2017, 8503754. [CrossRef] [PubMed]

26. Lagos, K.G.; Filippatos, T.D.; Tsimihodimos, V.; Gazi, I.F.; Rizos, C.; Tselepis, A.D.; Mikhailidis, D.P.; Elisaf, M.S. Alterations in the high density lipoprotein phenotype and HDL-associated enzymes in subjects with metabolic syndrome. Lipids 2009, 44, 9-16. [CrossRef] [PubMed]

27. Zeljkovic, A.; Vekic, J.; Spasojevic-Kalimanovska, V.; Jelic-Ivanovic, Z.; Bogavac-Stanojevic, N.; Gulan, B.; Spasic, S. LDL and HDL subclasses in acute ischemic stroke: prediction of risk and short-term mortality. Atherosclerosis 2010, 210, 548-554. [CrossRef] [PubMed]

28. Guo, B.; Li, Z. Endoplasmic reticulum stress in hepatic steatosis and inflammatory bowel diseases. Front. Genet. 2014, 5, 242. [CrossRef] [PubMed]

29. Wang, H.; Eckel, R.H. Lipoprotein lipase: from gene to obesity. Am. J. Physiol. Endocrinol. Metab. 2009, 297, E271-E288. [CrossRef]

30. Trak-Smayra, V.; Paradis, V.; Massart, J.; Nasser, S.; Jebara, V.; Fromenty, B. Pathology of the liver in obese and diabetic ob/ob and db/db mice fed a standard or high-calorie diet. Int. J. Exp. Pathol. 2011, 92, 413-421. [CrossRef]

31. Laperrousaz, E.; Moulle, V.S.; Denis, R.G.; Kassis, N.; Berland, C.; Colsch, B.; Fioramonti, X.; Philippe, E.; Lacombe, A.; Vanacker, C.; et al. Lipoprotein lipase in hypothalamus is a key regulator of body weight gain and glucose homeostasis in mice. Diabetologia 2017, 60, 1314-1324. [CrossRef] [PubMed]

32. Garcia-Arcos, I.; Hiyama, Y.; Drosatos, K.; Bharadwaj, K.G.; Hu, Y.; Son, N.H.; O’Byrne, S.M.; Chang, C.L.; Deckelbaum, R.J.; Takahashi, M.; et al. Adipose-specific lipoprotein lipase deficiency more profoundly affects brown than white fat biology. J. Biol. Chem. 2013, 288, 14046-14058. [CrossRef] [PubMed] 
33. Walton, R.G.; Zhu, B.; Unal, R.; Spencer, M.; Sunkara, M.; Morris, A.J.; Charnigo, R.; Katz, W.S.; Daugherty, A.; Howatt, D.A.; et al. Increasing adipocyte lipoprotein lipase improves glucose metabolism in high fat diet-induced obesity. J. Biol. Chem. 2015, 290, 11547-11556. [CrossRef] [PubMed]

34. Fujiwara, T.; Takami, N.; Misumi, Y.; Ikehara, Y. Nordihydroguaiaretic acid blocks protein transport in the secretory pathway causing redistribution of Golgi proteins into the endoplasmic reticulum. J. Biol. Chem. 1998, 273, 3068-3075. [CrossRef] [PubMed]

35. Murase, T.; Cattran, D.C.; Rubenstein, B.; Steiner, G. Inhibition of lipoprotein lipase by uremic plasma, a possible cause of hypertriglyceridemia. Metabolism 1975, 24, 1279-1286. [CrossRef]

36. Berbee, J.F.; van der Hoogt, C.C.; Sundararaman, D.; Havekes, L.M.; Rensen, P.C. Severe hypertriglyceridemia in human APOC1 transgenic mice is caused by apoC-I-induced inhibition of LPL. J. Lipid Res. 2005, 46, 297-306. [CrossRef] [PubMed]

37. Johansson, J.; Olsson, A.G.; Bergstrand, L.; Elinder, L.S.; Nilsson, S.; Erikson, U.; Molgaard, J.; Holme, I.; Walldius, G. Lowering of HDL2b by probucol partly explains the failure of the drug to affect femoral atherosclerosis in subjects with hypercholesterolemia. A Probucol Quantitative Regression Swedish Trial (PQRST) Report. Arterioscler. Thromb. Vasc. Biol. 1995, 15, 1049-1056. [CrossRef]

38. Watanabe, H.; Soderlund, S.; Soro-Paavonen, A.; Hiukka, A.; Leinonen, E.; Alagona, C.; Salonen, R.; Tuomainen, T.P.; Ehnholm, C.; Jauhiainen, M.; et al. Decreased high-density lipoprotein (HDL) particle size, prebeta-, and large HDL subspecies concentration in Finnish low-HDL families: relationship with intima-media thickness. Arterioscler. Thromb. Vasc. Biol. 2006, 26, 897-902. [CrossRef]

39. Stefanovic, A.; Kotur-Stevuljevic, J.; Spasic, S.; Vekic, J.; Zeljkovic, A.; Spasojevic-Kalimanovska, V.; Jelic-Ivanovic, Z. HDL 2 particles are associated with hyperglycaemia, lower PON1 activity and oxidative stress in type 2 diabetes mellitus patients. Clin. Biochem. 2010, 43, 1230-1235. [CrossRef]

40. Lee, M.; Jang, Y.; Kim, K.; Cho, H.; Jee, S.H.; Park, Y.; Kim, M.K. Relationship between HDL3 subclasses and waist circumferences on the prevalence of metabolic syndrome: KMSRI-Seoul Study. Atherosclerosis 2010, 213, 288-293. [CrossRef]

41. de Souza, J.A.; Vindis, C.; Hansel, B.; Negre-Salvayre, A.; Therond, P.; Serrano, C.V., Jr.; Chantepie, S.; Salvayre, R.; Bruckert, E.; Chapman, M.J.; et al. Metabolic syndrome features small, apolipoprotein A-I-poor, triglyceride-rich HDL3 particles with defective anti-apoptotic activity. Atherosclerosis 2008, 197, 84-94. [CrossRef] [PubMed]

42. Kontush, A.; Chantepie, S.; Chapman, M.J. Small, dense HDL particles exert potent protection of atherogenic LDL against oxidative stress. Arterioscler. Thromb. Vasc. Biol. 2003, 23, 1881-1888. [CrossRef] [PubMed]

43. Sakuma, N.; Yoshikawa, M.; Hibino, T.; Ohte, N.; Kamiya, T.; Kunimatsu, M.; Kimura, G.; Inoue, M. HDL3 exerts a more powerful antiperoxidative and protective effect against peroxidative modification of LDL than HDL2 does. J. Nutr. Sci. Vitaminol. (Tokyo) 2002, 48, 278-282. [CrossRef] [PubMed]

44. Camps, L.; Reina, M.; Llobera, M.; Bengtsson-Olivecrona, G.; Olivecrona, T.; Vilaro, S. Lipoprotein lipase in lungs, spleen, and liver: synthesis and distribution. J. Lipid Res. 1991, 32, 1877-1888. [PubMed]

45. Liu, G.; Xu, J.N.; Liu, D.; Ding, Q.; Liu, M.N.; Chen, R.; Fan, M.; Zhang, Y.; Zheng, C.; Zou, D.J.; et al. Regulation of plasma lipid homeostasis by hepatic lipoprotein lipase in adult mice. J. Lipid. Res. 2016, 57, 1155-1161. [CrossRef] [PubMed]

46. Bhattacharyya, S.; Dudeja, P.K.; Tobacman, J.K. Tumor necrosis factor alpha-induced inflammation is increased but apoptosis is inhibited by common food additive carrageenan. J. Biol. Chem. 2010, 285, 39511-39522. [CrossRef]

(C) 2019 by the authors. Licensee MDPI, Basel, Switzerland. This article is an open access article distributed under the terms and conditions of the Creative Commons Attribution (CC BY) license (http://creativecommons.org/licenses/by/4.0/). 